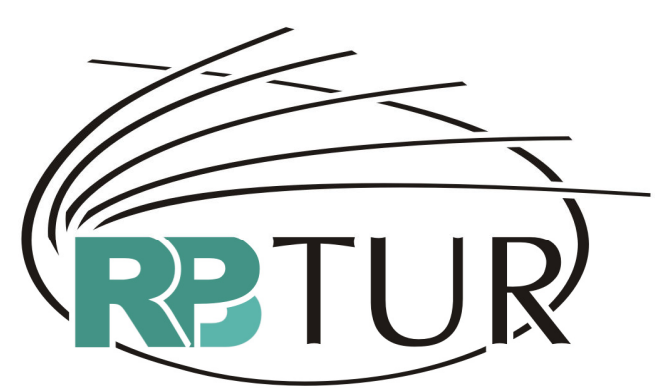

REVISTA BRASILEIRA DE PESQUISA EM TURISMO

\title{
ESTRUTURAÇÃO DE MATRIZ DE IMPACTOS DO TURISMO: O CASO DO AGROTURISMO NO MUNICÍPIO DE SANTA ROSA DE LIMA/SC ${ }^{1}$
}

\author{
STRUCTURING A MATRIX OF TOURISM IMPACTS \\ CAUSED BY THE DEVELOPMENT OF AGRITOURISM IN THE \\ MUNICIPALITY OF SANTA ROSA DE LIMA/SC \\ ESTRUCTURACIÓN DE UNA MATRIZ DE IMPACTOS DEL \\ TURISMO: EL CASO DEL AGRITURISMO EN EL MUNICIPIO \\ DE SANTA ROSA DE LIMA (SC)
}

Paulo dos Santos Pires ${ }^{2}$

Francisco Antonio dos Anjos ${ }^{3}$

Yolanda Flores e Silva ${ }^{4}$

Josildete Pereira de Oliveira ${ }^{5}$

\footnotetext{
${ }^{1}$ Artigo elaborado a partir do trabalho intitulado "Matriz de Impactos do Turismo no Meio Urbano e Rural do Município de Santa Rosa de Lima-SC", aprovado e apresentado no V ANPTUR - Seminário da Associação Nacional de Pesquisa e Pós-Graduação em Turismos no ano de 2008 em Belo Horizonte-MG.

2 Graduado em Engenharia Florestal pela UFSM-RS; Pós-Graduado em Fotointerpretação e Sensoriamento Remoto pela UFSM-RS; Pós Graduado em Turismo e Hotelaria pela UNIVALI; Mestre em Engenharia Florestal pela UFPR; Doutor em Ciências pela USP-SP. Pesquisador e docente do Programa de Mestrado em Turismo e Hotelaria. Contato: pires@univali.br

${ }^{3}$ Graduado em Geografia, Mestre em Geografia, Doutor em Gestão Ambiental, Pós-doutorado em Geografia Urbana/Ordenamento do Território, professor do Curso de Mestrado em Turismo e Hotelaria e do Doutorado em Administração em Turismo. E-mail: anjos@univali.br e fsanjos@terra.com.br

${ }^{4}$ Enfermeira / Antropóloga. Doutora em Filosofia da Saúde, docente e pesquisadora do Programa de Pós Graduação Stricto sensu em Turismo e Hotelaria - Mestrado Acadêmico da Universidade do Vale do Itajaí. E-mail: yolanda@univali.br e yolanda.flores@pq.cnpq.br

${ }^{5}$ Graduada em Arquitetura e Urbanismo pela Universidade Federal da Bahia, Master en Nature, Environnement, Société e Doutorado em Geografia pela Université de Caen-Basse NormandieFrança. Docente e Pesquisadora do Programa de Mestrado Acadêmico em Turismo e Hotelaria e do Curso de Arquitetura e Urbanismo da Universidade do Vale do Itajaí. E-mail: joliveira@univali.br
} 
PIRES, Paulo dos Santos; ANJOS, Francisco A.; OLIVEIRA, Josildete Pereira de. SILVA, Yolanda Flores e. Estruturação de matriz de impactos do turismo: o caso do agroturismo no município de Santa Rosa de Lima/SC. Revista Brasileira de Pesquisa em Turismo v. 3, n. 1, p. 68-89, abril 2009.

RESUMO: O desenvolvimento do turismo em áreas rurais e a avaliação de impactos no contexto do planejamento ambiental e ordenamento do território, constituem os dois principais eixos temáticos deste artigo que tem como objetivo estruturar uma matriz de impactos do turismo, adaptada do modelo universal da matriz de Leopold e aplicada ao município de Santa Rosa de Lima-SC, Brasil. A matriz contém em sua estrutura todas as atuações humanas relacionadas ao desenvolvimento do turismo (eixo vertical), bem como os âmbitos biofísico, sócio-cultural e econômico, potencialmente afetados por este desenvolvimento (eixo horizontal). A estruturação da matriz de impactos é produto de uma abordagem multi e interdisciplinar de uma pesquisa concluída em 2007, intitulada "Impactos e Riscos do Turismo nas Encostas da Serra Geral Catarinense - o caso de Santa Rosa de Lima". Como consideração final, aponta-se a perspectiva da aplicação propriamente dita da matriz de impactos, com a atribuição de valores de magnitude e de importância para cada atuação humana em cada âmbito afetado, ao mesmo tempo que se constata a escassez de literatura nacional e internacional sobre a aplicação de modelos matriciais para a avaliação de impactos da atividade turística, fato este que também instiga uma futura investigação.

Palavras-chave: Turismo. Agroturismo. Impactos do turismo. Matriz de Impactos do Turismo. Santa Rosa de Lima-SC.

ABSTRACT: The development of tourism in rural areas, and the evaluation of impacts in the context of environmental planning and territorial organization, are two of the main themes of this article, the objective of which is to structure a matrix of tourism impacts, adapted from the Leopold's universal matrix model, and applied to the municipality of Santa Rosa de Lima in t Santa Catarina State, Brazil. The structure of the matrix includes all human activities related to tourism development (vertical axis), as well as the biophysical, socio-cultural and economic environments, which are potentially affected by this development (horizontal axis). The structuring of the matrix of impacts is the result of the multi- and interdisciplinary approach conducted in a 2007 study, entitled "Impactos e Riscos do Turismo nas Encostas da Serra Geral Catarinense - o caso de Santa Rosa de Lima" (Impacts and Risks of Tourism on Serra Geral of Santa Catarina slopes). As final considerations, it forsees the practical application of the matrix of impacts, attributing values of magnitude and importance for each human activity in each of the affected environments. It also mentions the lack of national and international literature on the application of matrix models for evaluating the impacts of tourism activity, a fact which suggests the need for further research.

Key-words: Tourism. Agritourism. Tourism Impacts. Matrix of Tourism Impacts. Santa Rosa de Lima-SC.

RESUMEN: El desarrollo del turismo en areas rurales y la evaluación de impactos en el contexto de la planificación ambiental y la ordenación del territorio constituyen uno de los dos principales ejes temáticos de este artículo que tiene como objetivo estructurar una matriz de impactos del turismo, adaptada del modelo universal de la matriz de Leopold, y aplicada al municipio de Santa Rosa de Lima-SC, Brasil. La matriz contiene en su estructura todas las actuaciones humanas relacionadas al desarrollo del turismo (eje vertical), así como los ámbitos biofísico, socio-cultural y económico, potencialmente afectados por este desarrollo (eje horizontal). La estructuración de la matriz de impactos es producto de una aproximación multi e interdisciplinar de una investigación concluida en 2007 titulada "Impactos y Riesgos 
del Turismo en las laderas de la Serra Geral Catarinense- el caso de Santa Rosa de Lima". Como consideración final se menciona la perspectiva de la aplicación de esta matriz de impactos, con la atribución de valores de magnitud y de importancia para cada actuación humana en cada ámbito afectado, al mismo tiempo que se constata la escasez de literatura nacional e internacional sobre la aplicación de modelos matriciales para la evaluación de impactos de la actividad turística, hecho que también instiga para una futura investigación.

Palabras-clave: Turismo. Agroturismo. Impactos

\section{Introdução}

O turismo caracteriza-se pela sua complexidade devido à grande quantidade de elementos que o integram e pelos diferentes setores econômicos envolvidos em seu desenvolvimento, resultando na criação de empregos, geração de renda, entrada de divisas, aquecimento da atividade empresarial, entre outros efeitos econômicos benéficos que constituem o chamado "efeito multiplicador" do turismo, evidenciando a sua importância como atividade econômica geradora de riqueza (OMT, 2001 p. 10).

Por outro lado, a atividade turística nas comunidades locais e a geração de produtos e serviços para os visitantes, determinam transformações em suas estruturas nos âmbitos econômico, sócio-cultural e ambiental (GOELDNER et al, 2002), onde os impactos decorrentes e seus desdobramentos positivos e negativos nas localidades e regiões afetadas por esta atividade, se apresentam como matéria de investigação para a academia. Neste universo, para o enquadramento da presente abordagem se remeterá ao cenário identificado pela OMT (1999), pelo qual as novas motivações da demanda (sensibilidade ambiental, busca de autenticidade na experiência de viagem) associadas à eclosão de mercados com ênfase na natureza e na cultura, privilegiam enfoques positivos da relação turismo/destinos, enquanto que os enfoques negativos desta mesma relação deverão ser um fator crítico não só no planejamento como na orientação do desenvolvimento turístico. 
Neste sentido, a aplicação de técnicas mais precisas e específicas na gestão sócio-ambiental dos processos turísticos, aponta para a utilização de instrumentos que podem contribuir notavelmente em prol de sua competitividade e sustentabilidade. Entre estas técnicas e instrumentos, a "forma matricial" tem sido considerada como das mais adequadas para representar os impactos das atividades sobre o meio (ou território), já que permite cruzar facilmente as unidades ambientais inventariadas com as atividades, sua localização e funcionamento, entre elas o turismo (OREA, 1978; OMT, 1999).

Este artigo, portanto, centra-se na apresentação da matriz de impactos do turismo, enquanto instrumento de diagnóstico, aplicada ao município de Santa Rosa de Lima. A sua elaboração se deu no âmbito de um projeto ${ }^{6}$ desenvolvido como parte das atividades de pesquisa do Programa de Mestrado Acadêmico em Turismo e Hotelaria da Universidade do Vale do Itajaí-SC.

A elaboração das matrizes de impactos, tal como apresentadas, foi antecedida das seguintes etapas: a) estudos multidisciplinares voltados para a configuração do uso do solo da área de estudo; b) análise do desenvolvimento do turismo no município no contexto regional das Encostas da Serra Geral Catarinense; c) identificação/mapeamento dos riscos turísticos potenciais em Santa Rosa de Lima. Os procedimentos metodológicos do projeto de pesquisa que possibilitaram atender aos seus objetivos como um todo e, particularmente a elaboração das matrizes de impacto, incluíram: a) reuniões de trabalho da equipe executora; identificação a campo das atividades turísticas no município de SRL; levantamento da infraestutura básica e turística; identificação visual dos impactos ambientais; entrevistas individuais e

\footnotetext{
${ }^{6}$ Projeto de pesquisa financiado pelo CNPq (Edital Universal no 48.1964/04-5) intitulado "Impactos e Riscos do Turismo nas Encostas da Serra Geral Catarinense: o caso de Santa Rosa de Lima. Pesquisadores: Dr. Francisco A. Anjos; Dra. Josildete Pereira Oliveira; Dr. Paulo dos Santos Pires (Coordenador); Dra. Yolanda Flores e Silva. Colaboradores: Msc. Antônio Assef; Célia D. Uller; Msc. Fernando Protti Bueno; Msc. Maria Helena M. B. dos Santos; Msc. Marcos A. Junior; Msc. Thayse C. Grezzatti; Graduandos Bolsistas: Antônio Batista F. Neto; Graziane Zager; Gustavo P. Simonetti. Graduanda: Letícia Feüzer. Edição e formatação do relatório final: Msc. Luciana Noronha.
} 
PIRES, Paulo dos Santos; ANJOS, Francisco A.; OLIVEIRA, Josildete Pereira de. SILVA, Yolanda Flores e. Estruturação de matriz de impactos do turismo: o caso do agroturismo no município de Santa Rosa de Lima/SC. Revista Brasileira de

em grupos (grupo focal) com informantes locais; observação participante; e análise fotográfica.

O município objeto do estudo está localizado nas encostas da Serra Geral no Sul do estado de Santa Catarina (figura 1) e é nele que desde 1996 a Associação dos Agricultores Ecológicos das Encostas da Serra Geral - AGRECO, vem desenvolvendo um modelo de atividade agrícola livre do uso de agrotóxicos, resultante de produções orgânicas, que tem sido a base para o desenvolvimento de pequenas agroindústrias as quais, por sua vez, passaram a integrar a oferta turística na região, identificada como Agroturismo ${ }^{7}$.

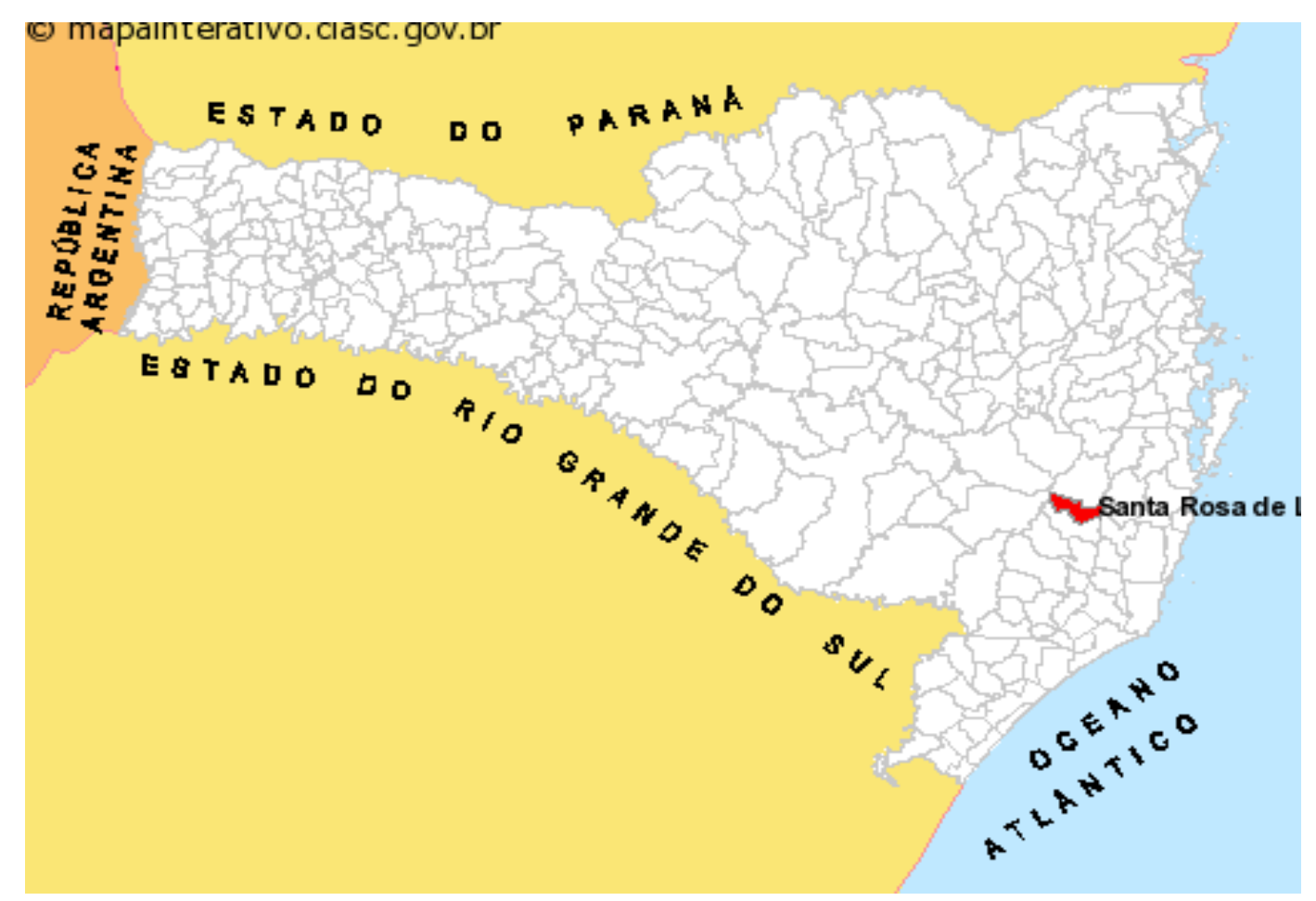

Figura 1: Localização de Santa Rosa de Lima no Estado de Santa Catarina Fonte: Governo do Estado de Santa Catarina (2000)

\footnotetext{
7 Agroturismo, segundo Guzzatti (2003), se caracteriza como uma modalidade alternativa de turismo, surgida a partir da busca de espaços naturais/rurais para descanso do ser humano moderno, que tem o ambiente natural como cenário e a apreciação do desenvolvimento rural sustentável como atrativo.
} 
As atividades do Agroturismo realizam-se nas propriedades rurais e os visitantes participam efetivamente do cotidiano das famílias que os hospedam. Estas atividades vêm modificando o cotidiano das famílias e do município receptor, interferindo de forma positiva e negativa no espaço natural, cultural e familiar da população local. Da mesma forma, vem transformando as relações de produção, trabalho, entretenimento, educação, cultura e saúde desta mesma população, justificando-se assim a investigação empírica dos impactos e riscos ambientais, econômicos e sócio-culturais que os visitantes e o turismo são capazes de causar (ULLER, 2005; PIRES et al, 2007; OLIVEIRA, 2009).

Além do esforço profissional multi e interdisciplinar exigido, este estudo encontrou o seu marco de referência bibliográfico basicamente no campo dos impactos do turismo e do planejamento e ordenamento territorial, cujos elementos teórico-conceituais essenciais serão a seguir expostos na forma de uma síntese compreensiva.

\section{MARCO TEÓRICO}

\subsection{Os impactos econômicos, sócio-culturais e ambientais do turismo}

O fenômeno do turismo traz consigo o deslocamento de pessoas e sua permanência fora de sua origem ou residência habitual, resultando em interferências nos lugares (destinos) e nos espaços de acesso aos mesmos. A estas interferências, dá-se o nome de impactos, onde:

O caráter dinâmico e multifacetado das relações de interdependência que se estabelecem no meio físico, juntamente com seus suportes ecológicos, e as atividades humanas no seu sentido mais amplo [...], levam a admitir que o desencadear do processo turístico produzirá, inevitavelmente, impactos de desdobramentos positivos e negativos com seus efeitos sinérgicos no tempo e no espaço, todos recaindo sobre o homem, a sociedade e o entorno natural (PIRES, 2001, p. 241). 
Cooper (2001) afirma, ainda, que além de positivos e negativos, os impactos podem ser associados ao desenvolvimento turístico de maneira direta, indireta e/ou ainda, induzida. Dada a sua amplitude, são usualmente identificados em três agrupamentos básicos: aqueles relacionados à economia das destinações; aqueles relacionados às características sócio-culturais da população anfitriã; e os associados aos aspectos naturais dos destinos.

\section{A) Sobre os impactos econômicos}

A atividade turística repercute de forma notória nas economias das regiões e países nos quais se desenvolve. Neste sentido, o turismo tem sido entendido como uma importante alternativa, especialmente para países com baixos níveis de emprego e distribuição de renda, de modo que a atividade pode propiciar um rápido incremento de divisas através dos gastos turísticos e os investimentos estrangeiros nas localidades receptoras:

Os geradores do impacto econômico para uma cidade, um estado, uma província, um país ou um destino são os visitantes, seus gastos e o efeito multiplicador. [...] Os destinos estão se tornando cada vez mais competitivos, já que um número crescente deles está se voltando para o turismo como grande gerador econômico, compensando a decadência nas atividades agrícola, mineradora e industrial (GOELDNER et al, 2002, p. 275).

Além disso, segundo Goeldner (2002), os impactos secundários gerados pelo fluxo de turismo, que incluem vendas e outros gastos além das despesas realizadas diretamente pelos setores de transporte, alimentação e hospedagem, determinam ganhos tributários e de receita, assim como geração de mais empregos em setores não vinculados diretamente à atividade em questão.

No entanto, mesmo com tantos benefícios econômicos e contribuições para o desenvolvimento local, o incremento da atividade turística traz consigo uma série de custos para as destinações. Deste modo, para uma correta avaliação dos impactos econômicos do turismo em determinada destinação, junto aos benefícios advindos desta atividade, também devem ser levados em 
conta seus respectivos custos para a economia dos receptores (SANCHO, 2001).

\section{B) Sobre os impactos sócio-culturais}

A implementação da atividade turística acaba por determinar, em maior ou menor grau, o encontro/contato entre turistas e a população local, seja quando o turista compra um bem ou serviço de um residente, ou quando os dois grupos convivem simultaneamente em territórios turísticos ou, ainda, quando estes estabelecem contato mais estreito pela troca de idéias e informações. Deste modo, segundo Sancho (2001, p. 215), "os impactos socioculturais, numa atividade turística, são resultado das relações sociais mantidas durante a estada dos visitantes, cuja intensidade e duração são afetadas por fatores espaciais e temporais restritos".

Entretanto, nem todas as modalidades turísticas permitem que estes contatos mais próximos se estabeleçam, como no caso do turismo de massa que em diversas ocasiões determina a criação de guetos favorecendo a segregação entre a população local e o turista. A presença do turista, assim com as diferenças de idiomas, de hábitos de consumo e comportamento social, valores religiosos e/ou éticos, podem ocasionar dificuldades de entendimento e de relacionamento entre visitantes e visitados (KRIPPENDORF, 1989). Entretanto, ainda que os impactos sócio-culturais sejam tradicionalmente abordados segundo seus aspectos negativos - ao contrário dos impactos

econômicos normalmente vistos segundo suas características positivas - é evidente a existência de benefícios decorrentes do contato entre diferentes grupos humanos.

O estabelecimento de regras e limites de atuação para a atividade turística segundo as características dos turistas e das localidades e população receptora, parecem ser importantes requisitos no sentido da potencialização dos efeitos sócio-culturais positivos do turismo. Assim, torna-se importante a aplicação de conceitos como o de capacidade de carga social e psicológica - a 
primeira aplicada aos residentes e a segunda, aos turistas; a participação da comunidade local nas definições e no planejamento da atividade e da utilização dos recursos, assim como, no usufruto dos benefícios decorrentes da atividade; e a conscientização dos turistas no que diz respeito à valorização da riqueza do entorno sócio-cultural receptor. Somente com a integração do elemento sócio-cultural ao planejamento territorial e turístico se é capaz de garantir um desenvolvimento integrado da comunidade receptora (SANCHO, 2001).

\section{C) Sobre os impactos ambientais}

De acordo com Cooper (2001), a presença de turistas e o "consumo" do "produto" turístico diretamente nos locais onde é originado, torna inevitável a associação da atividade turística aos impactos ambientais considerando que o meio biofísico, sobretudo o ambiente natural, são suportes indissociáveis dos destinos turísticos. Assim, uma das formas de degradação ambiental mais recorrente, gerada pelo desenvolvimento desordenado da atividade turística, é a destruição das paisagens naturais.

Segundo a mesma fonte (COOPER,2001), mesmo as modalidades turísticas consideradas menos destrutivas, não devem ser menosprezadas no que diz respeito aos seus impactos. A mudança de interesses turísticos evidenciados pela intensa segmentação de mercados, embora passe a buscar alternativas às destinações tradicionais e a exigir características específicas e sofisticadas pode, ao mesmo tempo, determinar uma maior preocupação ambiental, mas pode também determinar a utilização de ecossistemas frágeis, de alto valor ecológico, que correm maior risco de uma rápida e irreversível degradação.

Com relação especificamente ao ambiente natural, os impactos podem ser discriminados considerando os componentes biofísicos do meio, a saber: a vegetação; os solos; os recursos hídricos; a vida selvagem; o ar; as formações 
rochosas; os recursos minerais e os fósseis; e os efeitos sobre a paisagem em si, enquanto expressão espacial e visual do ambiente (PIRES, 2001).

A literatura especializada sobre o tema (impactos do turismo) já apresenta um considerável volume de abordagens e de contribuições acumuladas ao longo de mais de 30 anos, tanto para o campo da formação do conhecimento teórico e conceitual sobre o tema, quanto para a compreensão de sua dimensão empírica. Neste sentido, por exemplo, Butler (1974), Budowski (1976), Pizam (1978), Belisle e Roy (1980), Brougham e Butler (1981), Mathieson e Wall (1982), e Kuss, Graefe e Vaske (1990) constituemse em referências na elaboração das bases conceituais e teóricas, bem como de estruturas metodológicas e empíricas sobre os impactos do turismo.

Já com mais ênfase nas experiências e estudos aplicados, o conhecimento sobre os impactos do turismo em todas as suas dimensões encontra referências, entre outras, em: Pizam (1978), Belisle e Roy (1980), Brougham e Butler (1981), Milman e Pizam (1988), Sheldon e Var (1984), Liu, Sheldon e Var (1987), Mason (1990), Wearing e Neil (2000), Thyne, Lawson e Todd (2004), Stoeckl, Greiner e Mayocchi (2004), Mbaiwa (2003), Dyer, Aberdeen e Schuler (2003), e Gu e Ryan (2007).

Especificamente, as abordagens sobre os impactos do turismo em áreas naturais e sua gestão, podem ser encontradas em referências como Wagar (1964), Budowski (1976), Kuss, Graefe e Vaske (1990), Stankey et al (1985), CEAP (1992), Arias et al (1999), Buckey (1999), e mais recentemente em Eagles, McCool e Haynes (2002), Newsome, Moore e Dowling (2002), e Manfredo et al (2004).

\subsection{Planejamento do turismo}

O desenvolvimento da atividade turística depende de um conjunto de diferentes fatores que devem ser observados de maneira sistemática, já que estes elementos estão inter-relacionados e se desenvolvem de forma dinâmica e integrada. Os elementos básicos considerados para a realização e a 
existência da atividade turística são (1) a Demanda, (2) a Oferta, (3) o Espaço Geográfico e (4) os Operadores de Mercado (SANCHO, 2001).

Neste contexto e de acordo com Hall (2004), o planejamento tem sido visto como uma ferramenta utilizada com o objetivo de minimizar os impactos negativos, possibilitando um desenvolvimento mais próximo à sustentabilidade, pautado no equilíbrio e na visão de longo prazo, permitindo alcançar níveis de prolongamento do ciclo de vida do produto turístico. Planejar é uma ação que pretende ordenar, compreender e criar condições favoráveis para alcançar determinadas metas e/ou objetivos estabelecidos (RUSCHMANN, 1997). Neste âmbito, quando se tem em foco a atividade turística, o planejamento constitui-se no instrumento de desenvolvimento, a partir do qual define-se as prioridades de atuação seja do ponto de vista do produto com também do mercado, além de estabelecer as diretrizes e passo para regular e direcionar a atividade, em busca de seu crescimento equilibrado.

Olivares (2000) discute a importância do território como base para o desenvolvimento da atividade turística - e de todas as demais atividades humanas, de modo que o território constitui a principal matéria-prima para o desenvolvimento turístico, enquanto recurso capaz de atrair visitantes. Por outro lado, Sancho (2001) observa que a crescente exigência do mercado turístico, aliada às crescentes preocupações com o caráter natural e sócio cultural das destinações, evidencia a necessidade de novos enfoques e abordagens para o processo de planejamento e gestão do turismo, de modo que:

[...] a escolha do lugar onde será desenvolvido um novo atrativo, seu planejamento e gestão, deverá combinar o melhor uso por parte dos visitantes, a proteção dos interesses da população local, assim como os recursos que constituem o fundamento do referido atrativo (SANCHO, 2001, p. 124).

Portanto, no planejamento para a gestão do turismo, é necessário o desenvolvimento de etapas sugeridas por Sancho (2001), que incluem: a análise de desenvolvimentos turísticos anteriores; a avaliação da atual posição turística; a formulação da política turística; a definição da estratégia de 
desenvolvimento; além da elaboração de programas operativos. Assim, um Plano de Desenvolvimento Turístico deve levar em consideração estratégias de desenvolvimento que incluam os recursos humanos e o ambiente - entre o meio natural e o meio sócio-cultural.

\subsection{A avaliação de impactos no contexto do planejamento ambiental e do ordenamento do território}

Em escala mundial, com relação à proteção ambiental, as primeiras medidas administrativas de caráter preventivo adotadas há algumas décadas, foram as denominadas "Avaliações de Impacto Ambiental" aplicadas a obras ou atividades localizadas que podiam causar efeitos significativos nos ecossistemas Com a aplicação das Avaliações de Impacto Ambiental em projetos locais, observou-se a necessidade de adquirir delineamentos mais gerais, de caráter regional e territorial, que dessem embasamento técniconormativo às ações pontuais sobre o território. Era a noção de Planejamento Ambiental que começava a surgir, como uma alternativa de ordenamento das ações imprimidas pela sociedade contemporânea sobre o ambiente (SEDUE, 1988).

De acordo com a mesma fonte (SEDUE, 1988), na medida em que a idéia de planejamento ambiental foi amadurecendo na sua concepção, evidenciou-se a necessidade de materializar os princípios e pressupostos nela contidos, através da intervenção de instrumentos técnico-metodológicos aplicáveis à realidade sócio-econômica e territorial dos países e suas regiões. Surge então o conceito de Ordenamento do Território ou simplesmente Ordenamento Territorial, também chamado de Ordenamento Ecológico do Território ou ainda Ordenamento Econômico-Ecológico do Território. Seja qual for a expressão utilizada neste caso, pode-se considerar o ordenamento territorial como um processo de planejamento voltado para a avaliação e programação do uso do solo e o manejo dos recursos naturais, a nível regional, visando preservar e restaurar o equilíbrio ecológico e proteger o ambiente. 
Com isso, o processo de planejamento ambiental através do ordenamento do território pode se estruturar de acordo com duas linhas paralelas: a) uma linha de demanda que estuda a problemática econômica e social da população e define os objetivos a alcançar; e b) uma linha de oferta que examina as características do meio físico onde se desenvolvem e se desenvolverão as atividades humanas, definindo as possibilidades atuais e futuras para satisfazer tal demanda. Assim, a geração de alternativas de uso e ocupação do território, consiste em conseguir o ajuste entre ambas as linhas, e neste processo surgem os Planos de Ordenamento Territorial com caráter programático (de implantar programas aplicáveis) e alcance regional, através dos quais se determinam usos específicos do solo e normas para um aproveitamento racional e sustentado dos recursos naturais (FERNÁNDEZ et al 1979; OREA, 1979; IGNÁCIO et al 1984).

\subsection{0 modelo matricial de referência}

A noção de "impacto" incorporada a este estudo corresponde ao conceito exposto por Orea (1978) pelo qual, em essência, impacto é considerado a mudança de valor do meio (tomado no sentido amplo), como conseqüência da reação ou do tipo de resposta do mesmo ante influências externas.

Para representar os impactos das atividades humanas sobre o ambiente (ou território) a forma matricial tem sido considerada como das mais adequadas, já que permite cruzar facilmente as unidades ambientais inventariadas com as atividades objeto de localização (OREA, 1978). Entre as mais utilizadas estão as matrizes de interação e de identificação e as matrizes cruzadas, cujo cruzamento entre filas e colunas permite detectar todas as possíveis interações e valorá-las em termos de intensidade, extensão e importância, permitindo avaliar cada impacto produzido (OREA, 1978; OMT, 1999). A análise que suporta a construção da matriz não é uma estimativa quantitativa rigorosa, porém inclui juízos de valor que podem servir como guia 


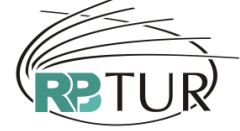

ISSN: $1982-6125$

para considerar alternativas de planejamento envolvendo valoração de impactos.

A configuração da matriz de análise se expressa com a definição das ações que causam impactos no eixo vertical, e com a definição dos fatores ou condições ambientais existentes que podem ser afetadas no eixo horizontal, assim como a definição dos fatores ou condições ambientais, sócio-culturais e econômicas existentes que podem ser afetadas. Este formato apresenta de forma compreensiva a grande quantidade de interações que ocorrem. A importância e a magnitude relativas dos impactos, que podem ser positivos ou negativos, se avaliam pontuando-se numa escala de 1 a 10 , precedidos de um sinal "+" ou "-" respectivamente para impactos positivos e negativos. A agregação total dos valores da matriz expressará o impacto atual ou previsível sobre o território estudado, provocado pelas atuações consideradas na análise (FERNÁNDEZ et al, 1979; IGNÁCIO et al, 1984).

\section{A matriz de impactos do turismo em Santa Rosa De Lima e considerações quanto à sua aplicação}

Adotou-se o modelo matricial universal de Leopold (1971) como base para a elaboração da Matriz de Impactos do Turismo no município de Santa Rosa de Lima, resultando nos modelos apresentados nas figuras 2 e 3.

Nota-se que as atuações relacionadas à infra-estrutura geral (rede viária, elétrica, de comunicações, de abastecimento etc.) e às instalações voltadas para o turismo (pousadas e complexo de águas termais), presentes na matriz de impactos correspondente à fase de expansão e desenvolvimento do agroturismo (período 2000-2007), não foram consideradas para a fase de implantação do agroturismo (período 1996-2000), uma vez que os possíveis impactos causados na ocasião não puderam ser levantados na presente pesquisa. 


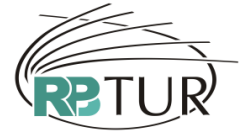

ISSN: 1982-6125
PIRES, Paulo dos Santos; ANJOS, Francisco A.; OLIVEIRA, Josildete Pereira de. SILVA, Yolanda Flores e. Estruturação de matriz de impactos do turismo: o caso do agroturismo no município de Santa Rosa de Lima/SC. Revista Brasileira de Pesquisa em Turismo v. 3, n. 1, p. 68-89, abril 2009.

Matriz de impactos e riscos do turismo em Santa Rosa de Lima = 1
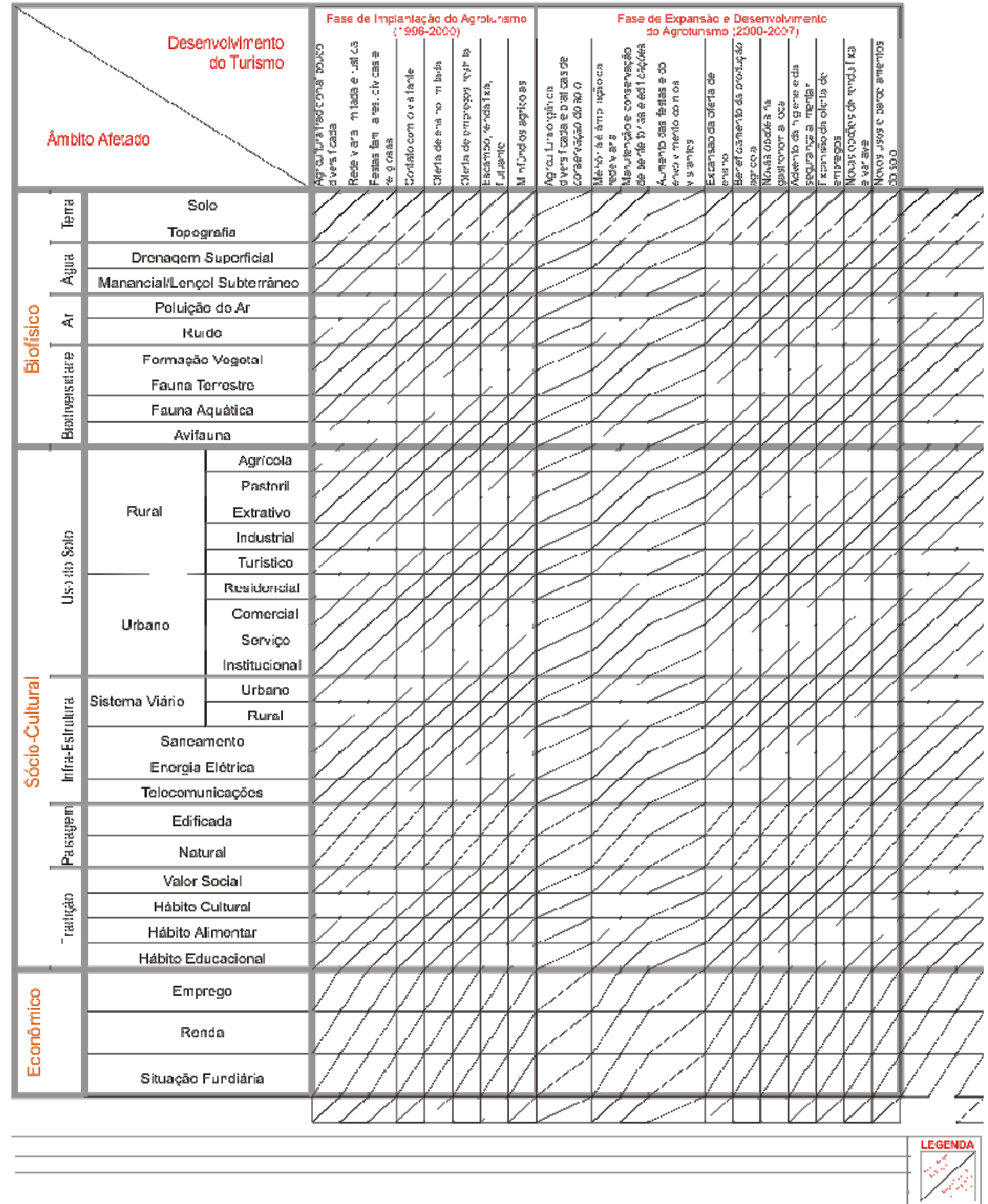

Figura 2: Matriz de impactos correspondente à fase de implantação do agroturismo (período 1996-2000). 
PIRES, Paulo dos Santos; ANJOS, Francisco A.; OLIVEIRA,

Matriz de impactos e riscos do turismo em Santa Rosa de Lima - 2

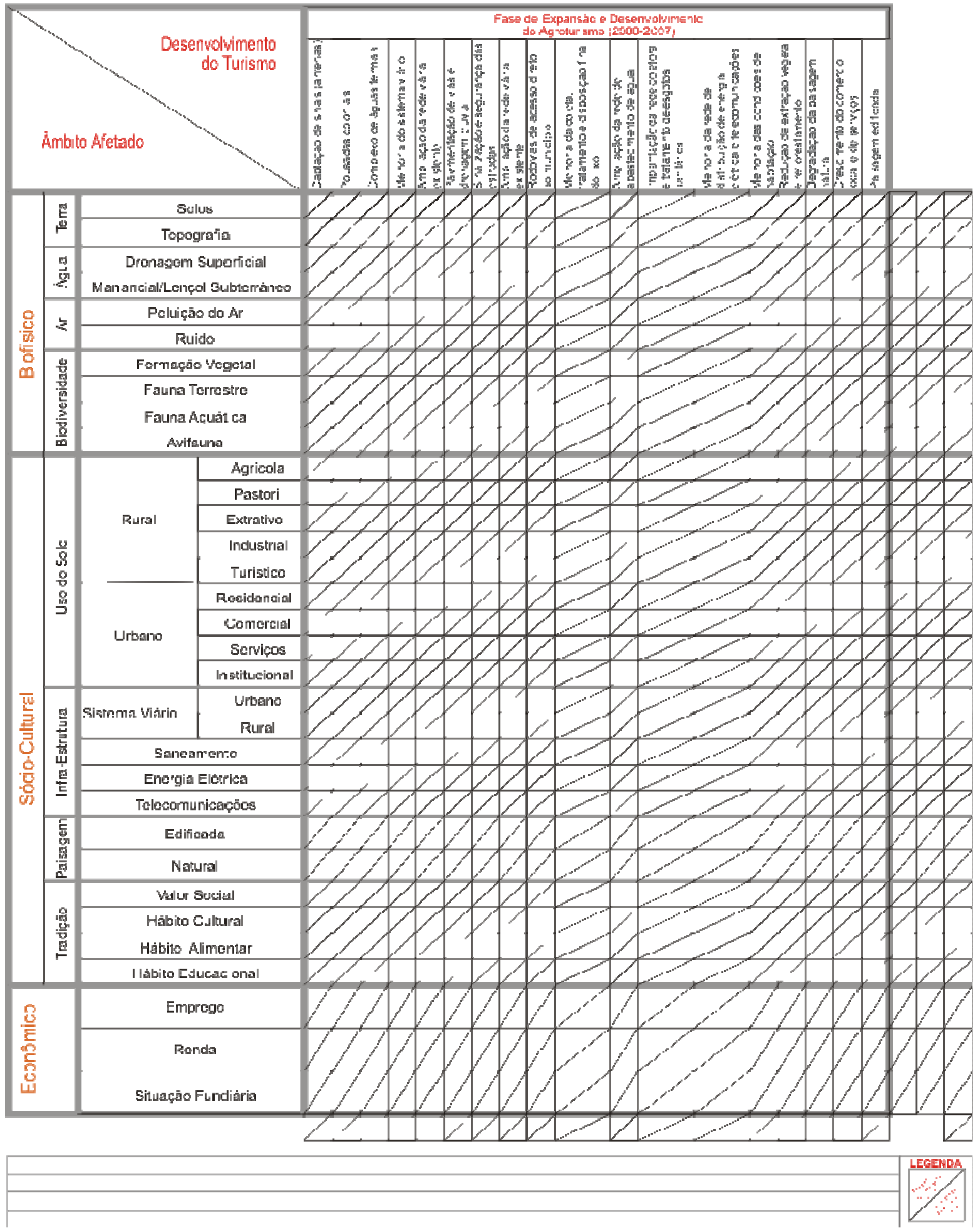

Figura 3: Matriz de impactos correspondente à fase de expansão e desenvolvimento do agroturismo (período 2000-2007).

Já os acontecimentos e processos de caráter sócio-cultural e econômico verificados no mesmo período de implantação do agroturismo (1996-2000), 
puderam ser considerados para efeito de sua inserção na matriz no período correspondentes a esta mesma fase já que, no mesmo, ocorreram pesquisas aplicadas no município dedicadas a este campo de abordagem com o envolvimento direto de uma das pesquisadoras participantes da equipe do presente projeto. Isso possibilitou que os resultados obtidos pudessem servir de base para a identificação dos referidos processos e acontecimentos.

A estrutura matricial elaborada compreendeu a inserção de todos os elementos e características ambientais de SRL potencialmente afetados pela implantação e desenvolvimento do agroturismo no município, assim como a inserção daquelas atuações ou atividades humanas relacionadas com tal processo. A estas foram incorporados novos âmbitos, principalmente quanto aos fatores sócio-econômicos e sócio-culturais, ampliando o alcance multidisciplinar para a aplicação da matriz, justamente em função das características multifacetadas do turismo e de seu desenvolvimento.

Porém, não foram atribuídos valores de magnitude e de importância em cada uma das células que correspondem graficamente ao cruzamento das linhas (elementos e características ambientais afetadas) com as colunas (desenvolvimento do turismo), bem como, não houve o processamento analítico para efeito de diagnóstico e planejamento do turismo. Assume-se estas etapas irão requerer uma nova abordagem já fora do alcance da pesquisa que se encerrou. Neste aspecto identifica-se, por exemplo, no trabalho de Puczkó e Rátz (2000) a aplicação do modelo matricial de Leopold para a determinação de impactos físicos do turismo, com a adoção de uma escala nominal (baixo/moderado/alto) de magnitude dos impactos benéficos e adversos.

Conforme constatam Puczkó e Rátz (2000) as matrizes tem sido utilizadas em relatórios de impacto ambiental e, por vezes, em auditorias ambientais como um instrumento apto na indicação dos impactos atuais de determinadas atividades ou de projetos em proposição. No entanto, citando Goodall (1995), os autores afirmam que o uso das matrizes no campo do turismo não está disseminado. Um raro exemplo aplicativo é, justamente, o 
trabalho realizado por Puczkó e Rátz (2000) na Hungria, em que a matriz de Leopold foi adotada para identificar impactos físicos do uso turístico, combinado com a análise da percepção dos residentes e turistas, no Lago Balaton, a segunda destinação turística do país em importância, depois de Budapest.

Em se tratando de outros modelos matriciais de análise aplicados a estudos no campo do turismo, que não o de Leopold, identificam-se trabalhos e estudos para a classificação e análise das atitudes e comportamentos de residentes em destinos turísticos rapidamente modificados (CARMICHAEL, 1999), bem como para o estudo do impacto da migração internacional de aposentados, seu nível de satisfação com o destino escolhido (Jalisco, México) e as ligações entre a migração e o turismo (TRULY, 2002). Por sua vez, Kwan e Glenn (2005) desenvolveram uma tipologia de percepção do custo-benefício de jogos e atividades de cassinos em Macau, com a adoção do que chamaram de "matriz de percepção de impactos do jogo", enquanto Raúl (2007) ao estimar o impacto do consumo oriundo do fluxo do turismo de eventos, incluiu entre os métodos utilizados um modelo de "matriz de contabilidade social", modelo este também adotado por Polo e Valle (2008) na avaliação do impacto econômico do turismo nas Ilhas Baleares. Por fim, mais um exemplo de adoção de modelos matriciais é obtido em González e Otero (2003), que desenvolveram uma metodologia de avaliação de impactos gerados pelo turismo alternativo no ambiente natural na Patagônia, com a utilização de "matrizes de valoração qualitativa de impactos ambientais e visuais".

Os exemplos destacados demonstram que estudos de natureza empírica focados nos impactos do turismo, podem adotar modelos matriciais, uns de natureza mais conceitual e estruturante e outros de caráter mais operativo caso da matriz de Leopold -, e que a aplicação de tais modelos contribui não só para a organização e sistematização dos dados, como para oferecer resultados passíveis de reprodução em distintos contextos e períodos do desenvolvimento do turismo. 


\section{Considerações finais}

Diante dos resultados alcançados pela pesquisa desenvolvida em SRL no que se refere à matriz de impactos do turismo, tem-se a perspectiva de instrumentalizar em um próximo estudo a atribuição de valores de magnitude e de importância destes impactos, bem como, o processamento analítico para efeito de diagnóstico e planejamento do turismo (Agroturismo) no município. Para tanto, será fundamental a participação de informantes da própria comunidade de SRL que vivenciaram os impactos do desenvolvimento do turismo em ambas as fases consideradas, quais sejam, a de implantação do agroturismo e a da sua expansão e desenvolvimento. Dessa forma, admite-se que novos fatores de impacto também poderão incorporar a atual matriz, ampliando-a e atualizando-a neste aspecto.

Quanto à constatação preliminar da escassez de referências bibliográficas na literatura internacional, com conteúdo e abordagens empíricas relativas à aplicação do modelo matricial de Leopold - ou mesmo de outros modelos matriciais - para a avaliação de impactos da atividade turística, há que se investir em levantamento mais exaustivo no sentido de tentar ampliar esta base referencial não só para permitir futuras análises comparativas, como para melhor refletir sobre a validade e efetividade da utilização de tal modelo, uma vez que parece se evidenciar uma contradição entre o que preconiza, por exemplo, a OMT sobre a utilidade de sua adoção nos estudos de impactos do turismo, e o parco advento do mesmo pela comunidade acadêmica envolvida com pesquisas na área.

\section{Referências}

ARIAS, M. C. et al. Capacidad de carga turística de las areas de uso public del Monumento Nacional Guayabo, Turrialba. n. 1. WWF-CATIE, 1999. (Serie Técnica).

BELISLE, F.; ROY, D. The perceived impact of tourism by residents. Annals of Tourism Research, U.K., v.7, n.1, p. 83-101, 1980. 
BROUGHAM, J.; BUTLER, R. A segmentation analysis of resident attitudes to social impacts of tourism. Annals of Tourism Research, U.K., v.7, n.4, p. 569-590, 1981.

BUCKEY, R. Tourism and biodiversity: land-use, planning and impact assessment. The Journal of Tourism Studies. Australia, V.10, n.2, 1999.

BUDOWSKI, G. Tourism and conservation: conflict, coexistence or symbiosis? Environmental Conservation, U.K., v.3, n.1, 1976.

BUTLER, R.W. Social implications of tourism development. Annals of Tourism Research, U.K., v.72 n.2, p. 100-111, 1974.

CARMICHAEL, B. A. A matrix model for resident attitudes and behaviors in a rapidly changing tourism area. Tourism Management, U.K., v. 21, p. 601-611, 1999.

CEAP-Centro de Estudios Ambientales y Políticas. Analisis de capacidad de carga para visitación em lãs áreas silvestres de Costa Rica. San José: Fundación Neotrópica, 1992.

COOPER, C. et al. Turismo: princípios e práticas. Tradutor: Roberto C. Costa. $2^{a}$ ed. Porto Alegre: Bookman, 2001.

DYER, P.; ABERDEEN, L.; SCHULER, S. Tourism impacts on an Australian indigenous community: a Djabugay case study. Tourism Management, U.K., v. 24, p. 83-95, 2003.

EAGLES, P.F.J.; McCool, S.F.; HAINES, C.D. Sustainable tourism in protected areas: guidelines for planning and management. Series n. 8. U.K.: Cardiff Universit/UNEP/WTO/UCN/WCPA, 2002. (Best Practice Protected Areas Guidelines).

FERNÁNDEZ, R.A. (y col.) Planificación física y ecologia: modelos y métodos. Madrid: EMESA, 1979.

GOELDNER, C. R. et al. Turismo: princípios, práticas e filosofias. Tradutor: Roberto C. Costa. $8^{a}$ ed. Porto Alegre: Bookman, 2002.

GONZÁLEZ, R.; OTERO, A. Método de evaluación cualitativa de impactos ambientales. Estudios y Perspectivas en Turismo. Buenos Aires, v.12, p. 79-92, 2003.

GU, H.; RYAN, C. Place attachement, identity and community impacts of tourism: the case of a Beijing hutong. Tourism Management, U.K., v. 29, p. 637-647, 2007.

GUZZATTI, T. C. 0 agroturismo como instrumentos de desenvolvimento rural: sistematização e análise das estratégias utilizadas para a implantação de um programa de agroturismo nas encostas da serra geral catarinense. Florianópolis, 2003. 148 f. Dissertação (Mestrado em Engenharia de Produção) - Programa de PósGraduação em Engenharia de Produção, Universidade Federal de Santa Catarina.

HALL, C. M. Planejamento turístico: políticas, processos e relacionamentos. São Paulo: Contexto, 2004.

IGNÁCIO y Col. Guia para la elaboración de estúdios del médio físico: contenido y metodologia. 2a ed. Madrid: CEOTMA, 1984.

KRIPPENDORF, J. Sociologia do Turismo: para uma nova compreensão do lazer e das viagens. Tradução: Contexto traduções Ltda. Rio de Janeiro: Civilização Brasileira, 1989. 
KUSS, F. R.; GRAEFE, A. R.; VASKE, J.J. Visitor impact management: a review of research. Washington D.C.: National Parks and Conservation Association, 1990. v. 1, IX.

KWAN, F.V.C.; GLENN, Mc C. Mapping resident perceptions of gaming impact. Journal of Travel Research, U.S.A, v.44, Issue 2, p. 177-187, 2005.

LEOPOLD, L.B. A procedure for evaluating environmental impact. Washington. D.C.: Geological Survey, 1971. (Circular 645).

LIU, J.; SHELDON, P.; VAR, T. A cross national approach to determining resident perceptions of the impact of tourism on the environment. Annals of Tourism Research, U.K., v.14, n.1, p. 17-37, 1987.

MANFREDO, M.J. et al. (org.) Society and Natural Resources: a summary of knowledge. Missouri: Modern Litho, 2004.

MASON, p. Tourism: environmental and development perspectives. London: WWF, 1990.

MATHIESON, A.; WALL, G. Tourism: economic physical and social impacts. New York: Longman, 1982.

MBAIWA, J.E. Enclave tourism and its socio-economic impacts in the Okavango Delta, Botswana. Tourism Management, U.K., v. 26, p. 157-172, 2003.

MILMAN, A.; PIZAM, A. Social impacts of tourism on central Florida. Annals of Tourism Research, U.K., v.15, n.2, p. 191-204, 1988.

NEWSOME, D.; MOORE, S. A.; DOWLING, R.K. Natural Area Tourism: ecology, impacts and management. Clevedon: Channel View Publications, 2002.

OLIVARES, D. L. El espacio turístico y el sistema turístico: los recursos territoriales turísticos. In: La ordenación y planificación integrada de los recursos territoriales turisticos. Madrid: Universidade Complutense, 1997.

OLIVEIRA, L.S. Agroturismo em Santa Rosa de Lima - SC: os discursos sobre o modelo implantado e a socialização do saber nas produções construídas de 2002 - 2007. Balneário Camboriú, 2009, 120f. Dissertação. (Mestrado em Turismo e Hotelaria). Centro de Comunicação, Turismo e Lazer. Universidade do Vale do Itajaí, 2009.

OMT. Agenda para planificadores locales: turismo sostenible y gestion municipal. (Edición para América Latina y Caribe). Madrid. 1999.

OMT. Guia de desenvolvimento do turismo sustentável. Tradutora: Sandra Netz. Porto Alegre: Bookman, 2003.

OREA, D.G. El médio físico y la planificación. Madrid: CIFCA. Gráficas Reunidas S/A. 1978.

PIRES, Paulo dos Santos. Interfaces ambientais do turismo. In: TRIGO, Luiz Gonzaga Godoi (Org.). Turismo: como aprender, como ensinar. 2a ed. São Paulo: SENAC, 2001.

PIRES, P. S. (org.). Impactos e riscos do turismo nas Encostas da Serra Geral Catarinense: o caso de Santa Rosa de Lima. Balneário, 2007, 118f. Relatório de Pesquisa (Mestrado em Turismo e Hotelaria / Conselho Nacional de Desenvolvimento Científico e Tecnológico). Universidade do Vale do Itajaí, 2007. 
PIZAM, A. Tourism impacts: the social costs to the destination community as perceived by its residents. Journal of Travel Research, U.S.A., v. 16 (spring), p. 8$12,1978$.

POLO, C.; VALLE, E. An assessment of the impact $f$ tourism in the Balearic Islands. Tourism Economics, U.K., v.14, Issue 3, p.615-630, 2008.

PUCZKÓ, L.; RÁTZ, T. Tourism and resident perceptions of the physical impacts of tourism at lake Balaton, Hungary: issues for sustainable tourism management. Journal of Sustainable Tourism. U.K., v. 8, n. 6, p. 458-78, 2000.

RAMOS, A. y col. Planificación física y ecologia. Madrid: EMESA. Litografia Josmar, 1979.

RAUL, H.M. Tourism events: impacts on imports. International Journal of Event Management Research, Australia, v.3, Issue 1, p.15-28, 2007.

RUSCHMANN, D. V. M. Turismo e planejamento sustentável: a proteção do meio ambiente. São Paulo: Papírus, 1997.

SANCHO, A. e Col. Introdução ao turismo. Tradutora: Dolores M. R. Corner. São Paulo: ROCA, 2001.

SEDUE-Secretaria de Desarrollo Urbano y Ecologia. Manual de ordenamiento ecologico del territorio. México, 1988.

SHELDON, P.; VAR, T. Resident attitudes to tourism in North Wales. Tourism Management, U.K., v. 5, n.1, p. 40-48, 1984.

STANKEY, G.H.; et al. The limits of acceptable change (LAC) system for wilderness planning. Utah. USDA, Forest Service, 1985. (General Technical Report INT-176).

STOECKL, N., GREINER, R., MAYOCCHI, C. The community impacts of different types of visitors: an empirical investigation of tourism in North-west Queensland. Tourism Management, U.K., v. 27, p. 97-112, 2004.

TRULY, D. International retirement migration and tourism along the lake Chapala Riviera: developing a matrix of retirement migration behavior. Tourism Geographies, U.K., v. 4, n. 3, p. 261-281, 2002.

THYNE, M.; LAWSON, R.; TODD, S. The use of conjoint analysis to assess the impact of the cross-cultural exchange between hosts and guests. Tourism Management, U.K., v. 27, p. 201-213, 2004).

ULLER, C. D. O agroturismo de Santa Rosa de Lima-SC: características e singularidades da hospedagem familiar. Balneário, 2005, 131f. Dissertação (Mestrado em Turismo e Hotelaria). Centro de Comunicação, Turismo e Lazer. Universidade do Vale do Itajaí, 2005.

WAGAR, J.A. The carryng capacity of wildlands for recreation. $n$. 7 ,. Washington D.C.: Society of American Foresters, 1964.

WEARING, S.; NEIL, J. Ecoturismo: impacto, tendências y posibilidades. Madrid: Sintesis, 2000. 